\title{
Selection of LRT system track gauge using multi-criteria decision-making (City of Zagreb)
}

\author{
L. Novačko, I. Ćavar \& D. Hozjan \\ Faculty of Transport and Traffic Sciences, University of Zagreb, Croatia
}

\begin{abstract}
Public urban passenger transit in the City of Zagreb consists of trams, buses and rail traffic. Constant growth of the motorization level in the City of Zagreb, and the existing condition of public urban transit, which fails more and more in satisfying the traffic demand, impose the need to introduce a new urban transport subsystem. In order to meet the current and future needs, and to improve the level of the quality of service, the introduction of a LRT (light rail transit) system is proposed, which has also been planned by the urban planning-traffic documentation of the City of Zagreb. One of the problems in the planning of the LRT system is the selection of the track gauge regarding the possibility of connection to the existing tram network, which uses $1000 \mathrm{~mm}$ (the railway network uses $1435 \mathrm{~mm}$ ). This paper applies the AHP method (Analytic Hierarchy Process) for the selection of the optimal track gauge, as one of the multi-criteria decision making methods. The hierarchic structure of all relevant criteria and their sub-criteria will be defined.
\end{abstract}

Keywords: LRT - light rail transit, AHP - analytic hierarchy process, public urban transport.

\section{Introduction}

As the capital of the Republic of Croatia, the City of Zagreb with 779,145 citizens is faced by the problem of sudden growth in individual traffic, especially for home-work trips, which results not only in the formation of forced traffic flows, but also in the reduction of the quality of living in the city itself. Due to the unsatisfactory level of service of the existing public urban transit, as well as because of the restrictions in raising this level, the City of Zagreb has decided on 
the development of a new subsystem - LRT (light rail transit). Since certain parts of the existing tram network are isolated compared to other transport modes, the usage of these track sections is proposed for LRT. The existing tram system in Zagreb uses a narrow gauge of $1000 \mathrm{~mm}$, and the experts have to solve the dilemma of whether to use the existing gauge or to decide, as the majority of other cities, on the normal gauge of $1435 \mathrm{~mm}$. As one of the methods of resolving this dilemma this paper proposes the usage of the multi-criteria analysis model.

\section{The existing condition of public urban transit in the City of Zagreb}

Like other transition cities, the City of Zagreb also features a strong and constant growth in the level of motorization. There are 0.90 passenger cars per household, and 417,215 passenger cars are registered (2006) [1] with an annual growth rate of about 20,000 vehicles. The growth rate in the level of motorization is also confirmed by the data that according to the Traffic Study for the City of Zagreb (MVA [6]) today's level of motorization had been predicted for as late as the year 2020.

On the other hand, opposite trends are present in public urban transit. Over the last two decades the investments in this transport mode have been negligible and have failed to follow demand. Over several recent years there have been investments into new tram and bus vehicles in order to raise the quality of service and into the development of traffic studies in order to improve the existing situation, which is awaiting a traffic coronary. However, the problem can no longer be solved by "fire-fighting measures". Rather, essential changes and respective investments are necessary.

Zagreb is literally in traffic coronary condition. Almost all the urban arteries and intersections are overburdened, and the interventions in the form of expansion by adding new lanes and grade separation of intersections have not yielded satisfactory results. The only effect of such measures is that the problem has merely been shifted from one node to another in the traffic network.

If we consider the load at about 200 signal controlled intersections in the considered zone as relation between traffic flows and capacity, the traffic load at about $40 \%$ of intersections in the morning peak hour exceeds the capacity $(\mathrm{Q} / \mathrm{C}>$ $1.00)$.

The additional problem is also the shortage of parking capacities in the city centre, thus forcing the motorists to circle for a long time searching for a free parking space. There is a shortage of about 2000-2500 parking spaces in Zagreb at the moment [2].

Public urban transit in Zagreb is not competitive with the individual traffic for the following reasons:

- lower speeds and longer travel times. The travel speeds on tram lines range between 12 and $16 \mathrm{~km} / \mathrm{h}$, and on buses between 15 and $25 \mathrm{~km} / \mathrm{h}$ [2]. The reasons lie primarily in the fact that the routes are not segregated from individual traffic on the big sections of the routes, that the motorists do not respect the lanes 
reserved for public urban transit vehicles and that there is no right-of-way system at the traffic lights. On the sections of lines where there is combination with individual vehicles, the travelling speed falls below $10 \mathrm{~km} / \mathrm{h}$;

- overload of the existing lines, i.e. insufficient capacity of the obsolete fleet;

- low level of service quality (in the last two years the quality of service has been increasing by introducing 70 low-floor trams with air-conditioning systems);

- unsatisfactory scope of coverage;

- poor condition of the infrastructure;

- lack of harmonization in the change of passengers at bus-tram terminals;

- absence of travel and pre-travel information of passengers;

- lack of reliability due to delays, etc.

As one of the essential reasons for introducing a new subsystem of public urban transit is the traffic safety on the streets of Zagreb. Because of the large number of vehicles, over the last five years there has been an average of 3500 victims of traffic accidents per year, out of which there were 50 fatalities.

Because of the above mentioned reasons and unless some major interventions in the public urban transit are carried out, in the morning peak hour in 2020 the number of passengers in individual traffic would increase by 41 percent, and in public urban transit by $6 \%$ [2]. Such prospects necessarily impose the need to consider a new underground and overground rail system.

Based on the research in the 1998 Traffic Study and in the Research Program of underground and surface rail system in the City of Zagreb (2006) the proposed solution is the introduction of LRT system as a subsystem of public urban transit in the City of Zagreb.

\section{LRT as a new subsystem of public urban transit in the City of Zagreb}

Regardless of the improvements in the tram network and the network of state railways, the enhancement possibilities in the centre of the city cannot be carried out because of the size and space organization from the $19^{\text {th }}$ century. The underground solution in the centre of the city is imposed as the only possibility, and overground or at level in the city peripheries. Based on a number of traffic analyses the metro system has not been accepted due to insufficient traffic demand, high price of construction and large inter-station distances. The LRT system has been selected as the most favourable solution, and because of cost rationalization it would also use a part of the existing tram network (on those sections on which it is segregated from motoring traffic).

The total number of trips in 2005 was 1.332 million, and 1.473 million trips are expected in 2020 [2]. Out of this number today only 40 percent are accounted for by public urban transit, with the tendency of further decline. The LRT system is the only system that can compete with individual traffic and prevent its chaotic growth for the following reasons:

- faster and shorter travel time compared to individual traffic;

- more reliable and safer (reduction in the number of traffic accidents in the city);

- not in collision with other transport modes; 
- higher level of the quality of service;

- cheaper transport;

- not depending on the weather conditions;

- environmentally friendlier;

- financially more acceptable compared to similar systems;

- higher standard of the quality of living in the city and relieving the traffic load in the city centre;

- increase in the land price and opening of new workplaces; etc.

The basic network of the future LRT system has been defined in the General Urban Plan of the City of Zagreb (2007), and in the space-traffic study (2007/2008) the basic verified network was supplemented by two corridors. The basic verified network consists of lines A and B, which connect the East and the West as well as the North and the South of the City [3]. Line C would connect the centre of the city with the airport, and line $\mathrm{D}$ would be a ring-line around the city (Figure 1).

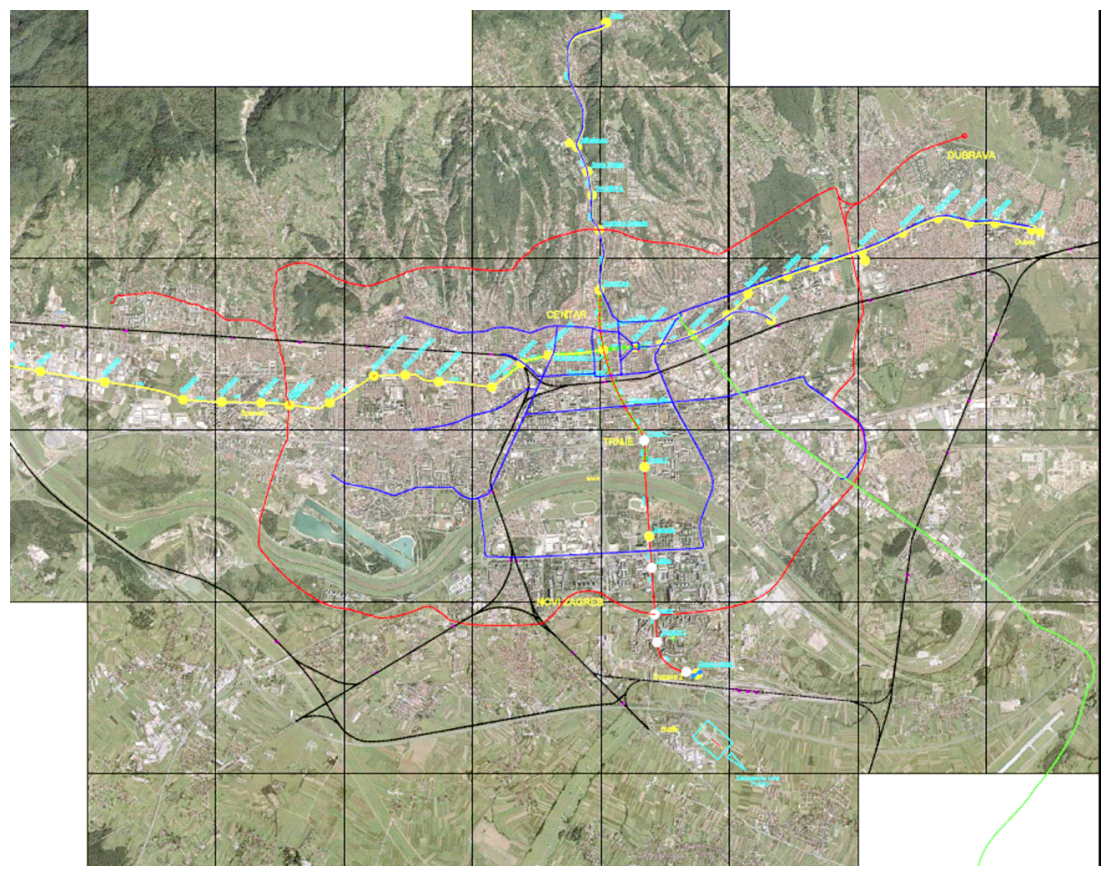

Figure 1: $\quad$ Basic LRT line network with additions.

\section{Problems of determining the gauge}

The General Urban Plan has not defined the gauge of the future LRT system and is still subject of further discussions. The tram network, namely, uses the gauge of $1000 \mathrm{~mm}$. Since the LRT system tracks would use sections of the existing network because of costs rationalization, and on the other hand, the majority of 
European countries uses the $1435 \mathrm{~mm}$ gauge (with the possibility of connecting to the railway network which passes through the centre of the city), the experts are faced by a justified dilemma regarding the selection of the optimal gauge.

The selection procedure of the better gauge, this paper applies the analytical hierarchy process (AHP).

\subsection{Analytical hierarchy process (AHP)}

In order to achieve the desired function of objective it is necessary to take into consideration all the relevant factors, with the consistency of the brought assessments in order to formulate correct conclusions. AHP represents a structured approach, which allows combination of logics and intuition in the decision-making procedure. It is based on three basic principles:

- creation of hierarchic structure of the studied problem;

- definition of priorities, and

- logic consistency.

Creation of the hierarchic structure of the considered problem represents the division of the system into components. The components yield information on the structure of the problem, and simplify the perception of the total system (Figure 2).

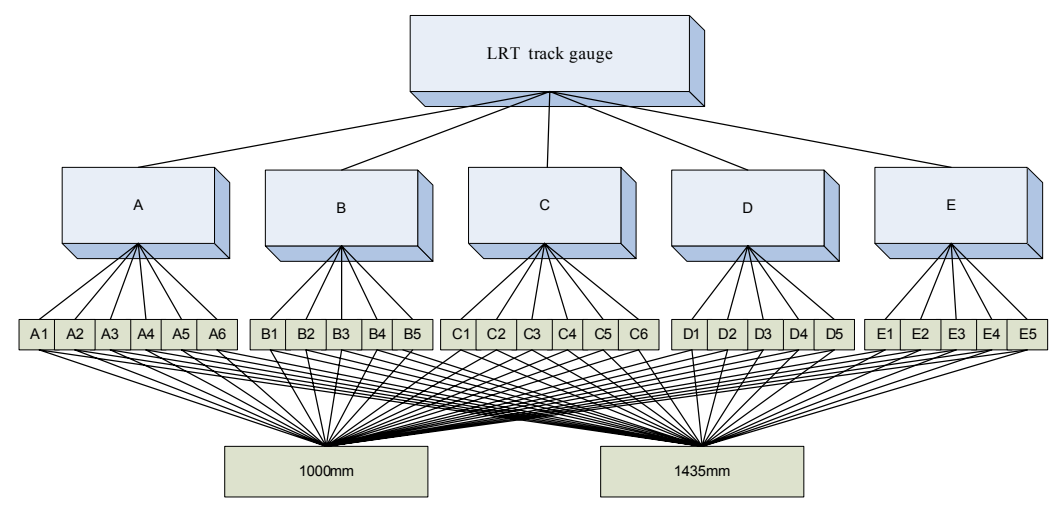

Figure 2: Hierarchic structure of the problem.

Definition of priorities understands comparison of elements at the same level of hierarchic structure in relation to the element at a higher level of hierarchy. Thus a matrix of intercomparisons is obtained. The elements at the same level of hierarchy in the comparison procedure have to have the same importance, since otherwise they need to be distributed into different levels of hierarchy. The intercomparison procedure of the elements at the same level of hierarchy, it is determined whether the elements have the same importance or one among them is more important than another [4].

The values of priorities for elements that are compared at the selected level of hierarchy follow by definition of matrix $T$ : 


$$
T=A+A^{2}+A^{3}+\ldots+A^{m}
$$

where $A$ is matrix of intercomparisons.

The alternative with the highest total priority is selected.

Logic consistency understands that the relations among the elements according to the set criterion have to be logical. There are two extremes that have to be taken into consideration; the first for which the decisions that have low consistency seem as if they had been selected at random, and the other one that it is difficult to achieve perfect consistency in practice. Therefore, the total acquired knowledge that has to be introduced in the decision-making process has to lie in the range of values between the lowest acceptable value and the perfect value of consistency.

Consistency index $C I$ is determined according to relation:

$$
\mathrm{Cl}=\frac{\lambda_{1}-\mathrm{n}}{\mathrm{n}-1}
$$

where $n$ is the number of rows, i.e. columns of the matrix and $\lambda$ is the eigenvalue.

Let $R C$ be average value of consistency for randomly selected matrices, then the consistency ratio $C R$ is:

$$
\mathrm{CR}=\frac{\mathrm{Cl}}{\mathrm{RC}}
$$

The acceptable values of the consistency ratio depend on the size of the intercomparison matrix. For matrix $3 \times 3$ the consistency ratio should not exceed 5 percent, 9 percent for matrix $4 \times 4$, and for bigger matrices it should not exceed 10 percent [5].

\subsection{Results of the research}

The assessment was carried out on a small number of experts; therefore, in order to verify the obtained results, it should be carried out on a larger number.

The results have shown that the most important criteria is Traffic with overall priority $54,7 \%$, followed by Operation and system maintenance with $17,1 \%$, Space/Urban planning (16,5\%), Construction/modality and expenses $(8,4 \%)$ and Fleet $(3,3 \%)$.

In the criteria Traffic the most significant sub-criteria is Transport capacity $(35,5 \%)$, in Operation and system maintenance Maintenance of operation and infrastructure (40,2\%) and in Space/Urban planning Development and incentive component.

Based on the criteria set in this way and the results obtained (Figure 3), the gauge of $1,435 \mathrm{~mm}$ has shown better results with $53.9 \%$ compared to that of $1,000 \mathrm{~mm}(46.1 \%)$.

\section{Conclusion}

The above stated facts and a rising price of fuel on the global market lead to the conclusion that public urban transport is the future of European cities. Although 
Figure 3: Overall alternative priorities.

the City of Zagreb became early aware of the impossibility of further individual traffic expansion, it has been investing little in the alternative public transport. Based on a number of surveys, the LRT system with underground and aboveground routes has been proposed as an optimal solution. Selecting the gauge width is one of the key dilemmas when designing the abovementioned system. It revolves around the question if it is better to use the parts of the existing tram network (the 1,000 gauge) with lower building costs, or, like most other cities, to opt for the gauge width of $1,435 \mathrm{~mm}$, with lower long-term maintenance costs. This article sets forth the proposal for an AHP analysis as a possible solution, as well as certain criteria and sub-criteria for further analyses.

\section{References}

[1] Statistical information, Republic of Croatia Central Bureau of Statistics, Zagreb, 2006.

[2] Research of underground - overground rail system in the City of Zagreb, Project results, Faculty of Transport and Traffic Sciences, University of Zagreb, 2006

[3] General Urban Plan, The City of Zagreb Official Courier, 10/2007

[4] T. L. Saaty: Decision Making for Leaders, RWS Publications, 1996.

[5] Ćavar, I.: Model izbora mobilnog uređaja u Republici Hrvatskoj primjenom AHP metode, diplomski rad (na hrvatskom), Fakultet prometnih znanosti, Sveučilište u Zagrebu, Zagreb, 2003.

[6] Zagreb Urban Transport Study, Final Report, MVA, Zagreb, 1999. 